\title{
Two new mutations in a late infantile Tay-Sachs patient are both in exon 1 of the $\beta$-hexosaminidase $\alpha$ subunit gene
}

\author{
Division of \\ Biomolecular \\ Sciences, King's \\ College London, \\ Campden Hill, \\ London W8 7AH. \\ D L Harmon \\ J L Stirling \\ Department of \\ Paediatric Neurology, \\ Newcastle General \\ Hospital, \\ Newcastle-upon-Tyne, \\ Tyne and Wear \\ NE4 6BE. \\ D Gardner-Medwin \\ Correspondence to \\ Dr Stirling. \\ Received 5 July 1992. \\ Revised version accepted \\ 28 August 1992
}

\begin{abstract}
We have identified two new point mutations in the $\beta$-hexosaminidase $\alpha$ subunit (HEX A) gene in a non-Jewish Tay-Sachs disease patient with an unusual late infantile onset disease phenotype. The patient was a compound heterozygote with each allele of the HEX A gene containing a different mutation in exon 1 . One of these is a $\mathbf{T}$ to $\mathrm{C}$ transition in the initiation codon, expected to produce no $\alpha$ subunit and therefore a classical infantile phenotype. The unusual clinical aspects and later onset in the patient must therefore be a result of residual hexosaminidase $A$ activity associated with a mutant $\alpha$ subunit containing the second mutation, substitution of serine for proline at amino acid 25 owing to a $C$ to $T$ change at nucleotide 73. Western blotting and DE52 ion exchange chromatography have been used to examine the behaviour of this mutant $\alpha$ subunit.

(f Med Genet 1993;30:123-8)
\end{abstract}

The lysosomal storage disorder Tay-Sachs disease (TSD) is one of the $\mathrm{G}_{\mathrm{M} 2}$-gangliosidoses, so called because storage of ganglioside $G_{M 2}$ in neuronal lysosomes is the cause of neurodegeneration. ${ }^{1} \mathrm{G}_{\mathrm{M} 2}$ is the substrate of the lysosomal enzyme hexosaminidase $A$ which consists of two highly homologous subunits, $\alpha$ and $\beta$, which are encoded by structurally related genes on chromosomes 15 and 5 respectively. Mutations in the $\alpha$ subunit gene are responsible for TSD, which is inherited in an autosomal recessive manner

TSD alleles are found at a high frequency in the Ashkenazi Jewish population (heterozygote frequency $1 / 31$ ), where three mutations ${ }^{2-4}$ are responsible for the majority of cases and DNA based carrier detection and prenatal diagnosis are therefore straightforward. However, the lower incidence in the general population $(1 / 167)^{1}$ is associated with numerous mutations, often private, and mostly of the point mutation type.

TSD is classified according to age of onset. The most severe form is classical infantile TSD which presents with motor weakness and increased startle reaction at 3 to 5 months of age, and is invariably associated with macular cherry red spots on ophthalmological examination. Neurological signs become increasingly evident with loss of vision, seizures usually beginning after the first year, and progressive macrocephaly. Further deterioration ends in an unresponsive vegetative state and death at 2 to 4 years of age. This phenotype is common to all patients with complete hexosaminidase A deficiency.

Later onset phenotypes are more clinically variable and are usually divided into juvenile, adult, and chronic forms. Juvenile TSD presents between 2 and 6 years of age followed by progressive dementia, increasing spasticity, seizures by the end of the first decade, and finally a vegetative state and death at 10 to 15 years of age. Chronic forms have similar onset, but are much milder with cerebellar signs prominent, and patients live into adulthood. Adult onset forms vary considerably even within families and are not clearly distinguished from chronic TSD. ${ }^{56}$ Macular cherry red spots are not a consistent finding in these later onset phenotypes. All adult patients have been found to possess the same $\alpha$ subunit mutation $^{4}$ (Gly 269 to Ser), the effects of which at the enzyme level have been well studied. ${ }^{7}$ It is thought to disrupt association of the $\alpha$ subunit with the $\beta$ subunit, an event which is necessary for activity and for targeting to the lysosome. ${ }^{8}$ The diversity of symptoms which result are an indication of the difficulties of correlating abnormal $\alpha$ subunit behaviour with disease phenotype. Another mutation of the $\alpha$ subunit (Arg 504 to His), that apparently affects dimerisation, results in juvenile TSD. ${ }^{9}$

The proband had an unusual phenotype intermediate between classical infantile and juvenile TSD. Similar late infantile patients have been described previously. ${ }^{10}$ One mutation has been characterised in a late infantile patient, and this is a silent base change at the last nucleotide of exon 5 resulting in missplicing of the primary transcript and a much reduced ( $3 \%$ of control) level of normal hexosaminidase A. ${ }^{11}$ Two new mutations were found in our patient and metabolic studies indicate that $\alpha$ subunit containing the Pro 25 to Ser mutation exhibits behaviour similar to that of the Gly 269 to Ser mutant subunit of adult onset patients.

\section{Case report}

CLINICAL DESCRIPTION

The proband was the only child of healthy, unrelated, non-Jewish English parents aged 19 and 20 years. Her gestation and birth were normal. She suffered from infantile eczema and asthma, otherwise her general health was normal. Early developmental milestones were all normal and she was able to walk unsupported at 11 months. She first came to medical 
attention at the age of 2 years 5 months with a story of ataxia of gait for the previous five days which her mother thought was because of pain following a fall. Enquiry showed that her gait had always been rather slow and clumsy and she had never learned to run. There was comparable delay in speech with the development of only six words and no phrases and it appeared that her overt ataxia had been present for at least one month.

On examination she had severe truncal ataxia and marked clumsiness of the hands with a palmar grasp and no pincer grasp. There was no tremor of the upper limbs. All the tendon reflexes were brisk but the plantar responses were flexor. There was a mild degree of oculomotor apraxia without nystagmus. Vision and hearing appeared to be normal. There was a moderately exaggerated startle to clap which rapidly habituated.

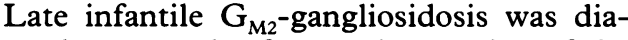
gnosed as a result of general screening of the lysosomal enzymes. Electrolytes, liver function, blood biotinidase, $\alpha$ fetoprotein, and immunoglobulins were normal. A CT scan showed slight ventricular dilatation and a cavum septum pellucidum but no other abnormality.

Her subsequent course was rapidly progressive. Two months after presentation she had definite spasticity, extensor plantar responses, and early optic atrophy. Cherry red spots of the macula were identified at 2 years 11 months, but throughout life remained inconspicuous. She was unable to walk by 2 years 10 months and by 3 years her vision was markedly impaired with very impaired sitting balance, severe dysarthria, and dementia. At 2 years 11 months, following a severe asthmatic attack without significant hypoxia, she developed some choreiform movements with an athetoid component which settled over the period of one week. By 3 years 9 months the spasticity was severe but she was still able to roll over, to creep in the prone position, and sometimes vocalise responsively. By then her only visual response was partial eye closure to bright light. She was found dead in bed at the age of 4 years 2 months.

Her head circumference at 2 years 5 months was $48.0 \mathrm{~cm}$ (just above the 25 th centile) and subsequent repeated measurements showed very slow growth so that at 3 years 10 months it was $48.4 \mathrm{~cm}$ (10th centile).

Necropsy (by Dr R H Perry) showed extensive petechial haemorrhages on the inferior aspect of the heart suggesting the possibility of asphyxia but no other abnormalities of the general organs. The brain weighed $1040 \mathrm{~g}$. There was macroscopic evidence of abnormal myelination in the centrum semiovale with accentuation of subarcuate fibre markings. Histological examination showed neuronal storage PAS positive material compatible with $\mathrm{G}_{\mathrm{M} 2}$-gangliosidosis in the frontal, temporal, parietal, and occipital cortex principally in the magnocellular pyramidal neurones (with relative sparing of the granule cells) including the end plate, CA3, and CA2 regions of the hippocampus. Sommer's sector was spared. The motor neurones of the brain stem (including the III and IV nerve nuclei) and spinal cord were severely affected with gross distension of many anterior horn cells and of the neurones of Clark's columns. The cerebellum, including the dentate nuclei, Purkinje cells, and granular cells, was only minimally involved. However, the pontine nuclei were affected. Ultrastructural abnormalities included membranous cytoplasmic bodies entirely compatible with Tay-Sachs disease.

\section{ENZYMOLOGICAL STUDIES}

Enzyme assays

Activity of $\beta$-hexosaminidase $A$ and $B$ in fibroblast extracts was assayed using 4-methylumbelliferyl $\beta$ - $\mathrm{N}$-acetylglucosamine (4-MUGlcNAc), and 4-methylumbelliferyl $\beta$ $\mathrm{N}$-acetylglucosamine 6-sulphate (4-MUGlcNAc6- $\mathrm{SO}_{4}$ ) was used to assay for the $\mathrm{A}$ isoenzyme specifically as described by Beccari et al. ${ }^{12}$ Activity of $\beta$-hexosaminidase isoenzymes secreted into the medium was measured similarly except that in order to detect activity against 4-MUGlcNAc-6- $\mathrm{SO}_{4}$ in medium harvested from the proband's fibroblasts it was necessary to increase the lysosomal enzyme secretion by growth with ammonium chloride $(10 \mathrm{mmol} / \mathrm{l})$, and to concentrate the medium by precipitation with ammonium sulphate $(0.52 \mathrm{~g} / \mathrm{ml})$, redissolving the protein pellet in one twentieth of the original volume of phosphate buffer, and dialysing against the same buffer, before assay.

\section{$D E A E$ cellulose chromatography}

Cell extracts were prepared from fibroblast cultures grown in $\alpha$-MEM (Gibco) containing $10 \%$ NuSerum (Collaborative Research, Bedford, UK). Sonicated extracts were applied to a $3 \mathrm{ml} \mathrm{DE}-52$ (Whatman) column equilibrated with $10 \mathrm{mmol} / 1$ sodium phosphate buffer, $\mathrm{pH} 6 \cdot 0$. After the unretained $\mathrm{B}$ peak had been eluted, the remaining isoenzymes were separated in a NaCl gradient (0 to $0.3 \mathrm{~mol} / 1$ in $70 \mathrm{ml}$ of the column buffer).

\section{Western blotting}

SDS PAGE was carried out on $10 \%$ polyacrylamide gels according to the method of Laemmli. ${ }^{13}$ Proteins were electroblotted onto nitrocellulose (Hybond-C Extra, Amersham), blocked with $5 \%$ skimmed milk, and reacted with first antibody for two hours, followed by washing and reaction with second antibody for 90 minutes. Antipeptide antiserum specific for the hexosaminidase $\alpha$ subunit was raised against four synthetic peptides from the $\alpha$ subunit by $\mathrm{Dr} R$ Hosseini in this laboratory, and purified on a protein-A Sepharose column before use. The Amersham ECL detection system was used to visualise binding of the HRP conjugated goat antirabbit IgG (BioRad) used as second antibody. 
CHARACTERISATION OF MUTATIONS

mRNA was extracted from fibroblast cultures by the method of Birnboim ${ }^{14}$ and passed through an Oligo-dT-Cellulose column (Oligo-dT-Cellulose Type 7, Pharmacia) to purify the polyadenylated fraction. This was transcribed in the presence of actinomycin $D$ with M-MuLV Reverse Transcriptase (Pharmacia) using an oligo-dT primer. Polymerase chain reaction (PCR) was carried out using a battery of exonic oligonucleotides to amplify overlapping segments of cDNA sequence (table), and the PCR products were purified using Geneclean (Bio 101 Inc, La Jolla, California) and digested with restriction enzymes at natural sites in the $\alpha$ gene for cloning. Oligonucleotides are denoted by the cDNA number of their most $3^{\prime}$ base and $F$ or $R$ for forward (primes coding strand) or reverse (primes non-coding strand).

The strategy was amplification of exons 1 to 4 with $153 \mathrm{~F}$ and $440 \mathrm{R}$ and digestion with $\mathrm{Taq} \mathrm{I}$ at its single exon 1 site (184 bp into the exon) and $\mathrm{SacI}$ in exon 2 (TaqI digested fragments may be cloned into $A c c \mathrm{I}$ digested M13 vectors). Exons 2 to 9 were amplified with oligonucleotides $291 \mathrm{~F}$ and $994 \mathrm{R}$, followed by digestion at natural $S a c I$ sites in exons 2 and 6 for cloning. Amplification of exons 6 to 12 with $602 \mathrm{~F}$ and $1336 \mathrm{R}$ and digestion with $\mathrm{SacI}$ in exon 6 and Asp 718 in exons 11 and 12 gave a SacI-Asp 718 fragment spanning exons 6 to 11 and an Asp 718-Asp 718 fragment covering exons 11 and 12. Amplification of exons 11 to 14 with $1292 \mathrm{~F}$ and $1608 \mathrm{R}$ (the latter in the $3^{\prime}$ non-coding region), and digestion with Asp 718 at the exon 12 site and EcoRI at a site introduced into the $5^{\prime}$ end of the reverse oligonucleotide, completed the coding sequence with the exception of the beginning of exon 1 .

The $5^{\prime}$ end of exon 1 together with the putative promoter region was amplified from genomic DNA (extracted from fibroblasts by standard methods) using oligonucleotides in the $5^{\prime}$ non-coding region $(-439 \mathrm{~F})$ and in exon 1 (178R), and digested with TaqI at sites 310 bases upstream of the coding sequence and in exon 1 (the exon $1 \mathrm{Taq}$ I site is also in the 178R primer), thus completing the coding sequence. The 3 ' non-coding region including the polyadenylation sites was also amplified from genomic DNA with oligonucleotides at $1593 \mathrm{~F}$ and 2215R, and digested for cloning with HindIII and $X b a \mathrm{I}$, sites for which had been incorporated in the $5^{\prime}$ end of the primers.

The digested products were excised from $0.8 \%$ low melting point agarose gels, ligated

Oligonucleotides used to amplify the hexosaminidase $\alpha$ subunit cDNA and genomic sequences of exons 1 and 14 for cloning.

\begin{aligned} & \hline$-439 \mathrm{~F}$ 5'-TAAGCTTGAGCTCTGAAGTTACTTCAGCC-3' \\ & 153F 5'-TCCAGTACGATGTCAGC-3' \\ & 178R 5'-AAGGCCTCGTCGAGGAC-3' \\ & 291F 5'-AGAAGAATGTGTTGGTTGTC-3' \\ & 440R 5'-GCCCTCAGCAGATTTCC-3' \\ & 602F 5'-GGCGTACAATAAATTGAACGTGTT-3' \\ & 994R 5'-CATAAAGTCCTGGATCTCTGGGTT-3' \\ & 1292F 5'-CCGTATATCCTATGGCCCTGACTG-3' \\ & 1336R 5'-AATCACCAGAGCCTTCTGCTCAGG-3' \\ & 1593F 5'-AGAGCTCAAGCTTGAACAGACCTGAGCC-3' \\ & 1608R 5'-GGAGCTCGAATTCACCTACAGCCAGCACCC-3' \\ & 2215R 5'-AGGATCCTCTAGAGAACAATATGTG-3' \\ & \hline\end{aligned}

into M13 vectors mp18 and mp19 (Pharmacia), and sequenced by Sanger dideoxy chain termination using M13 and hexosaminidase specific primers and the Sequenase Version 2 enzyme and kit (United States Biochemical Corp). Several clones of each fragment were sequenced to eliminate PCR mutations from consideration. No PCR mutation has so far been detected twice. Genuine mutations were confirmed by repeating the procedure from the amplification stage, to eliminate the possibility of an error in an early PCR cycle giving more than one mutant clone.

The $\mathrm{C}$ to $\mathrm{T}$ change at position 73 in the DNA coding sequence creates a new AvaII site (GGTCC). This was used to confirm heterozygosity for this mutation in the proband, and could be used for screening purposes. Oligonucleotides used to amplify this region of cDNA for cloning and digestion purposes were $-439 \mathrm{~F}$ in the $5^{\prime}$ non-coding region, and $178 \mathrm{R}$ which primes the non-coding strand in the reverse direction in exon 1. The PCR products were purified on Geneclean, digested with AvaII, and electrophoresed on $20 \%$ acrylamide gels. The normal digestion pattern is two fragments of 300 and $325 \mathrm{bp}$, the mutant pattern is 300,205 , and $120 \mathrm{bp}$ bands. Heterozygosity is indicated by the presence of $300,325,205$, and $120 \mathrm{bp}$ fragments.

\section{Results}

Hexosaminidase A activity of the cell extract as measured using 4-MUGlcNAc-6- $\mathrm{SO}_{4}$ was less than $2.5 \%$ of that found in a normal fibroblast cell line. The ratio of activity against 4MUGlcNAc-6-SO ${ }_{4} / 4-M U G l c N A c$ secreted into the medium by the proband's fibroblasts was identical to that found intracellularly, implying that secretion of the mutant $\alpha$ subunit was normal.

Fig 1 shows the separation of $\beta$-hexosaminidase isoenzymes by DE- 52 column chromatography in a $\mathrm{NaCl}$ gradient. The proband showed neither a sharp A peak, as in the normal cell line, nor the large intermediate peak observed in classical Ashkenazi TaySachs cell lines. Instead, there was a small, broad peak that could contain both forms, but there was no detectable activity towards the sulphated substrate. This was similar to the profile obtained for an Ashkenazi Jewish adult onset patient heterozygous for the Gly 269 to Ser association defective mutation.

$\beta$-hexosaminidase $\alpha$ subunit polypeptides separated from fibroblast extracts on SDSpolyacrylamide gels were detected with an anti-( $\alpha$ subunit peptide) serum after western blotting (fig 2). Comparison with normal fibroblasts and with those from a patient with Ashkenazi infantile onset Tay-Sachs disease showed that the patient's fibroblasts contained no mature $54 \mathrm{kDa} \alpha$ subunit (the lysosomal processed form), but that $\alpha$ precursor of apparently normal size $(67 \mathrm{kDa})$ was present.

Only two reproducible changes were detected in the entire DNA sequence. These were both in clones containing part of exon 1 

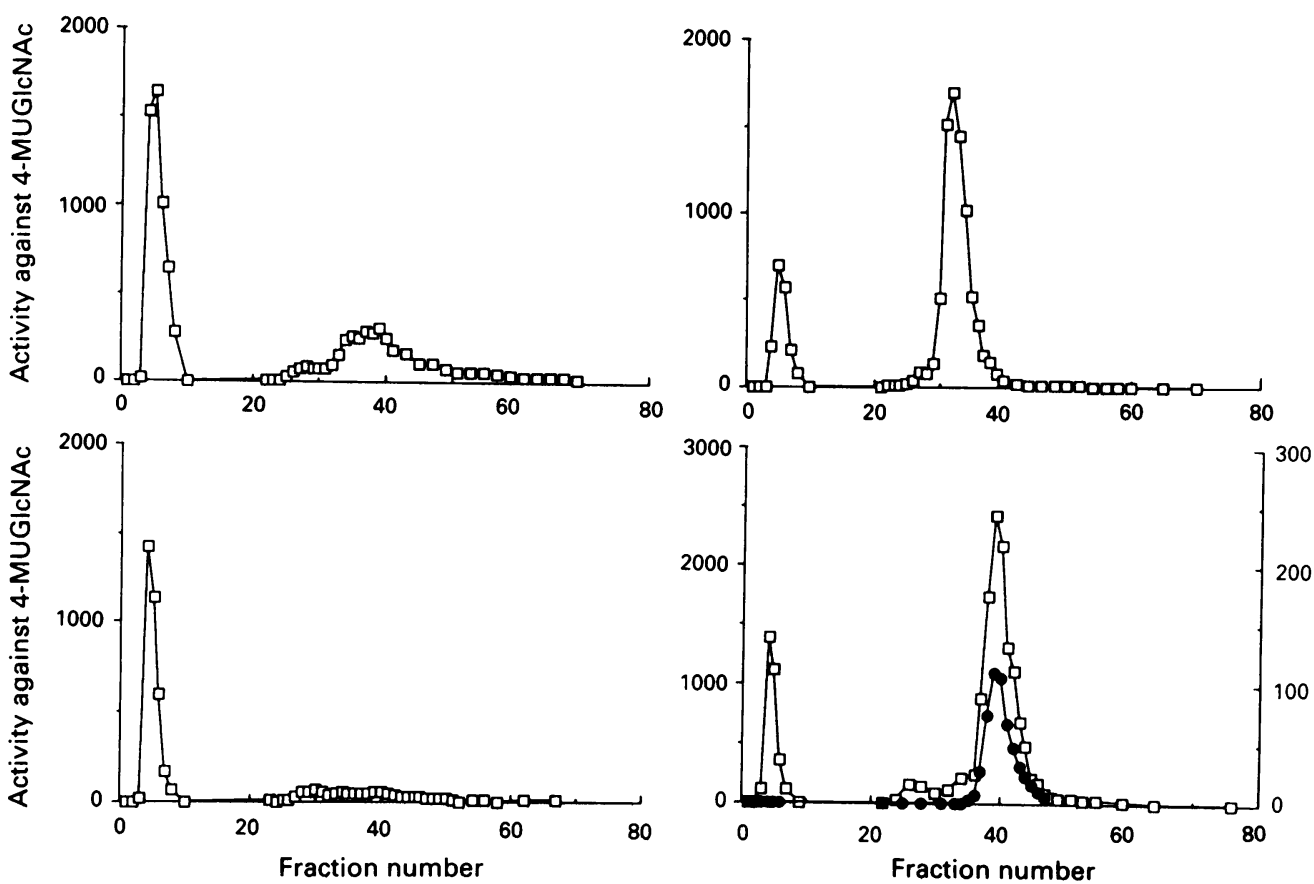

Figure 1 Hexosaminidase isoenzymes were separated by DE-52 cellulose chromatography. Sonicated fibroblast extracts containing equal amounts of protein were applied to a $3 \mathrm{ml} D E-52$ column and $1 \cdot 2$ ml fractions were collected. The $B$ isoenzyme was not retained, while the $A$ isoenzyme was eluted in the NaCl gradient $(0$ to 0.3 mol/l in $70 \mathrm{ml}$ ) which began at fraction 20. Activities against 4-MUGlcNAc (open squares, left axis) and 4-MUGlcNAc-6-SO (filled circles, right axis) are shown in relative fluorescence units. The upper left hand profile is that of the late infantile patient in question. For comparison, the upper right is that of a classical infantile patient, the lower right is from a normal control, and the lower left hand profile is from an adult onset patient with the Gly 269 to Ser mutation in heterozygosity with the common exon 11 insertion.

that had been amplified from genomic DNA with the oligonucleotides given. All clones sequenced contained either a $\mathrm{T}$ to $\mathrm{C}$ transition at the second base of the initiation codon (ATG to ACG), or a $\mathrm{C}$ to $\mathrm{T}$ change at nucleotide 73 (fig 3). No clone had normal sequence in both positions, and no clone contained both changes. The $\mathrm{C}$ to $\mathrm{T}$ change at position 73 would result in the replacement of proline 25 with a serine residue. Heterozygosity for the $\mathrm{C}$ to $\mathrm{T}$ change was additionally confirmed by digestion with $A v a \mathrm{II}$ at the new site resulting from the mutation (not shown), and it is suggested this test may be useful for screening patients of similar phenotype.

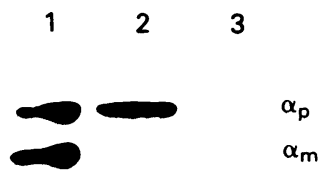

\section{Discussion}

The clinical course in our patient differed from classical Tay-Sachs disease in its late onset, the prominence of early ataxia, the absence of macrocephaly, seizures, or excessive startle myoclonus, and the inconspicuousness of the cherry red spots on the maculae. The course was more rapid than in most cases of juvenile $\mathrm{G}_{\mathrm{M}_{2}}$-gangliosidosis. The post mortem histology and hexosaminidase assay provided

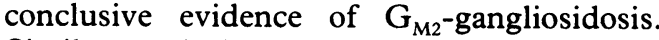
Similar atypical late infantile cases have occasionally been reported (cases 2 and 3 in Brett et $\left.a l^{10}\right)$ but the nature of the mutations in these cases is unknown.

Initiation codon mutations have been found to be responsible in cases of several inherited diseases. These include the same $T$ to $C$ change in the $\alpha 2$ globin gene which leads to $\alpha$ thalassaemia. ${ }^{15} \mathrm{~A}$ mutation to ATA in the ornithine- $\delta$-aminotransferase gene causes gyrate atrophy of the choroid and retina, ${ }^{16}$ and a GTG initiation codon mutation in the apoCII gene causes a deficiency of apolipoprotein CII. ${ }^{17}$ There is no possible in frame alternative ATG in the hexosaminidase $\alpha$ subunit gene.

A few examples of non-ATG initiation are now known, and include the use of CTG in the human c-myc gene. ${ }^{18}$ Non-AUG initiation has recently been shown to take place in vivo under conditions of transient expression in cultured cells, ACG being the best alternative, ${ }^{19}$ but methionine is still the initiating amino acid. Should the mutated initiation codon still be functional in this case any enzyme produced would therefore be entirely normal, but enzymological evidence indicates this is not so. The initiation codon mutation can hence be assumed to be a null allele which 

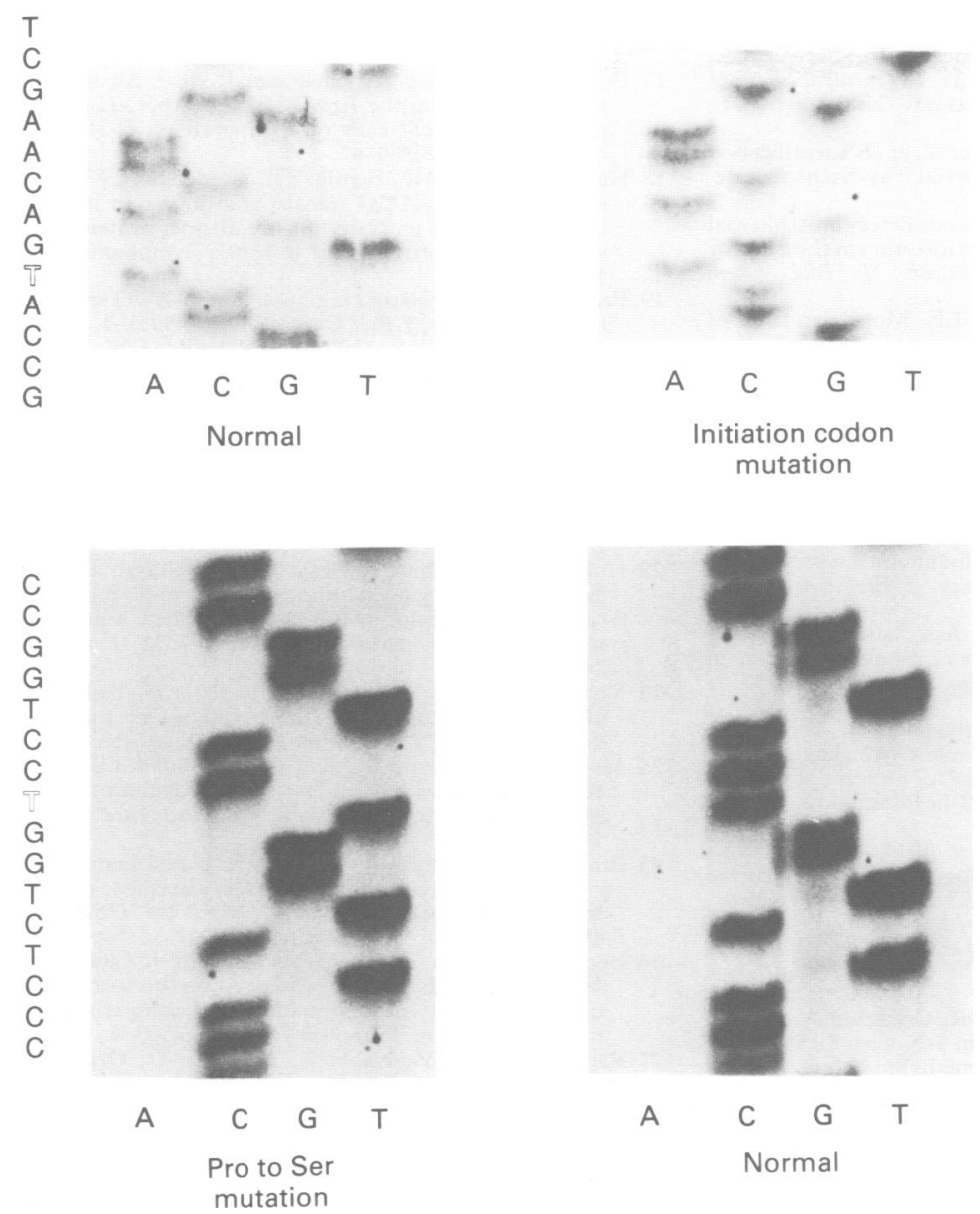

Figure 3 Sequences of parts of two M13 clones containing exon 1 of the HEX $A$ gene. In the top panel the normal sequence of the left hand clone is seen, while the right hand clone contains a $T$ to $C$ change in the initiation codon. In the lower panel the right hand clone is normal, while the left hand clone contains a $C$ to $T$ change at nucleotide 73 , which causes substitution of proline 25 by serine.

would produce the classical disease phenotype. A different initiation codon mutation (ATG to GTG) has recently been reported in a patient with the classical TSD phenotype. ${ }^{20}$

The Pro 25 to Ser change is of particular interest owing to its position in the $\mathrm{N}$-terminal region encoded by exon 1 , a region of poor amino acid homology with the $\beta$ subunit, where gene structure also diverges to such a degree that it has been suggested that exon 1 arose from intron sliding or exon shuffling during the evolution of the two genes from a common ancestor. ${ }^{21}$ The 'precursor' polypeptide encoded by exon 1 is in fact proteolytically cleaved from the 'mature' polypeptide in the lysosome, but remains attached to it by a disulphide bridge. ${ }^{22}$ It has been suggested that this region is responsible for the many dif-

H 19 RATALW P WPQNFQTSDQRYVLYPNNFQFQYDVSSAAQPGCSVLDEAFQRY $|1| 1|||| 1|:| 1 \ldots|1.11| 1|1| 1 . .11|1| 1.11|1| .|1| . \mid 1$ M 19 LATALW P WPQYIQTYHRRYTLYPNNFQFRTHVSSAAQGGCVVLAEAFRRY

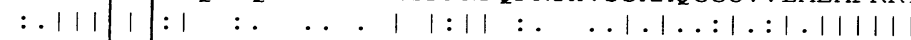
H $\beta 52$ PGPALW P LPLSVKMTPNLLHLAPENFYISHSPNSTAGPSCTLLEEAFRRY $.||||||:||||.||.|.::|:|||||||||||||||| 1:.|||||| \mid$ MB31 LQPALW P FPRSVQMFPRLLYISAEDF SIDHSPNSTAGP SCSLLQEAFRRY

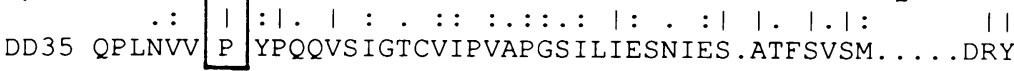

Figure 4 Alignment of hexosaminidase sequences. Solid lines indicate identity of amino acid residues in the human hexosaminidase $\alpha$ subunit $(H \alpha)$, mouse hexosaminidase $\alpha$ subunit $(M \alpha)$, human hexosaminidase $\beta$ subunit $(H \beta)$, mouse hexosaminidase $\beta$ subunit $(M \beta)$, and Dictyostelium hexosaminidase (DD). Pro 25 of the human hexosaminidase $\alpha$ subunit is boxed. ferent properties of the otherwise similar $\alpha$ and $\beta$ subunits, including substrate specificity, differing dimerisation behaviour, and interaction with the $\mathrm{G}_{\mathrm{M} 2}$ activator protein. ${ }^{23}$ However, this mutation, which occurs only three amino acids into the precursor from the site of signal peptide cleavage, has led us to compare the $\mathrm{N}$ termini of not only human $\alpha^{24}$ and $\beta$ subunits, ${ }^{25}$ but of mouse $\alpha^{26}$ and $\beta$ subunits, ${ }^{27}$ and hexosaminidase from Dictyostelium discoideum. ${ }^{28}$ The alignment of these sequences illustrated in fig 4 showed that Pro 25 is one of two prolines conserved in all these proteins, and it is likely that it is necessary for reasons common to all hexosaminidase subunits.

This work has indicated that, unlike some mutant $\alpha$ subunits which are thought to be retained in the endoplasmic reticulum, ${ }^{92}$ the Pro 25 to Ser mutant can be secreted by fibroblasts as can mutant polypeptides previously described as association defective. The DE-52 profile indicates the effect of the mutation is not on activity of the $\alpha$ subunit alone as in the $\mathrm{B} 1$ variant, ${ }^{30}$ as for the latter a normal $\mathrm{A}$ peak is observed with 4-MUGIcNAc owing to $\beta$ subunit activity of the dimer. The $\alpha$ subunit of the proband's fibroblasts is unable to reach the lysosome as shown by its lack of lysosomal processing, and residual hexosaminidase A activity is negligible. It is therefore probable that the mutation, directly or indirectly, prevents dimerisation with the $\beta$ subunit.

It has been found that specific genotypes do consistently give rise to certain Tay-Sachs disease phenotypes, for example, the Gly 269 to Ser mutation to chronic or adult disease, and the B1 mutation to juvenile onset disease. However, the correlation of phenotype with the defect at the enzyme level has not been possible (for example, mutations thought to disrupt subunit association cause adult and juvenile phenotypes), and there are two possible reasons. Firstly, small variations in the residual intralysosomal activity resulting from such mutations may have a large effect on the age of onset. It has been estimated that $10 \%$ of normal hexosaminidase activity is compatible with normal health, ${ }^{1}$ and therefore phenotypic differences may result from differences in residual associated $\alpha$ subunit present below the limits of detection. It is also important to remember that lysosomal enzyme metabolism in the affected neurones may differ from that in the fibroblasts used in metabolic studies. It is known, for example, that while fibroblasts direct acid hydrolases to the lysosome entirely by means of the mannose-6-phosphate recognition pathway, neurones are able to use an additional pathway independent of mannose phosphorylation, the nature of which is unknown. Hence an enzyme which is unable to reach the lysosome in one cell type may be normally targeted in another, and similar differences with respect to the biosynthesis of hexosaminidase A may render results obtained with fibroblasts unrepresentative of the situation in neurones.

DLH was the recipient of a Wellcome Trust Prize Studentship. 
1 Sandhoff K, Conzelmann E, Neufeld EF, Kaback MM, Suzuki K. The $\mathrm{G}_{\mathrm{M} 2}$ gangliosidoses. In: Scriver $\mathrm{CR}$ Beaudet AC, Sly WS, Valle D, eds. The metabolic basis of inherited diseases. New York: McGraw-Hill, 1989:180739.

2 Arpaia E, Dumbrille-Ross A, Maler T, et al. Identification of an altered splice site in Ashkenazi Tay-Sachs disease. Nature 1988;333:85-6.

3 Myerowitz R, Costigan FC. The major defect in Ashkenaz Jews with Tay-Sachs disease is an insertion in the gene for the $\alpha$-chain of $\beta$-hexosaminidase. $f$ Biol Chem 1988;263:18587-9.

4 Paw BH, Kaback MM, Neufeld EF. Molecular basis of adult-onset and chronic $\mathrm{G}_{\mathrm{M}_{2}}$ gangliosidoses in patients of Ashkenazi Jewish origin: substitution of serine for glycine at position 269 of the $\alpha$-subunit of $\beta$-hexosaminidase. Proc Natl Acad Sci USA 1989;86:2413-7.

5 Navon R, Argov Z, Frisch A. Hexosaminidase A deficiency in adults. Am f Med Genet 1986;24:179-96.

6 Navon R. Molecular and clinical heterogeneity of adult $G_{M 2}$ gangliosidosis. Dev Neurosci 1991;13:295-8.

7 d'Azzo A, Proia RL, Kolodny EH, Kaback MM, Neufeld EF. Faulty association of $\alpha$-and $\beta$-subunits in some forms EF. Faulty association of $\alpha$-and $\beta$-subunits in some forms of $\beta$-hexosamin

8 Proia RL, d'Azzo A, Neufeld EF. Association of $\alpha$ - and $\beta$ subunits during the biosynthesis of $\beta$-hexosaminidase in cultured human fibroblasts. F Biol Chem 1984;259:33504.

9 Paw BH, Moskowitz SM, Uhrhammer N, Wright $\mathrm{N}$, Kaback MM, Neufeld EF. Juvenile GM2 gangliosidosis caused by substitution of histidine for arginine at positio 499 or 504 of the $\alpha$-subunit of $\beta$-hexosaminidase. $7 \mathrm{Bio}$ Chem 1990;265:9452-7.

10 Brett EM, Ellis RB, Haas $\mathrm{L}$, et al. Late onset $\mathrm{G}_{\mathrm{M2}^{-}}$ gangliosidosis: clinical, pathological and biochemical
studies on 8 patients. Arch Dis Child 1973;48:775-85.

11 Akli S, Chelly J, Mezard C, Gandy S, Kahn A, Poenaru L. A ' $G$ ' to ' $A$ ' mutation at position -1 of a 5 ' splice site in late infantile form of Tay-Sachs disease. $7 \mathrm{Biol}$ Chem 1990;265:7324-30.

12 Beccari T, Emiliani C, Hosseini R, Orlacchio A, Stirling $\mathrm{JL}$. Intermediate forms of human $\beta-\mathrm{N}$-acetylhexosaminidase lack activity towards 4-methylumbelliferyl $\beta-\mathrm{N}$ acetylglucosaminide-6-sulphate. Biochem $f$ 1987;244: $801-4$

13 Laemmli UK. Cleavage of structural proteins during the assembly of the head of bacteriophage T4. Natur 1970;227:680-5.

14 Birnboim HC. Rapid extraction of high molecular weight RNA from cultured cells and granulocytes for Northern analysis. Nucleic Acids Res 1988;16:1487-97.

15 Pirastu M, Saglio G, Chang JC, Cao A, Kan YW. Initiation codon mutation as a cause of $\alpha$ thalassemia. $\mathcal{F}$ Biol Chem 1984;259:12315-7.

16 Mitchell GA, Brody LC, Looney J, et al. An initiator codon mutation in ornithine- $\delta$-aminotransferase causing gyrate atrophy of the choroid and retina. $f$ Clin Invest 1988;81:630-3.

17 Fojo SS, de Gennes JL, Chapman J, et al. An initiation codon mutation in the ApoC-II gene (ApoC-II
patient with a deficiency of apolipoprotein C-II. 3 Biol patient with a deficiency

18 Hann SR, King MW, Bentley DL, Anderson CW, Eisenman RN. A non-AUG translational initiation in c-myc exon 1 generates an $\mathrm{N}$-terminally distinct protein whose synthesis is disrupted in Burkitt's lymphomas. Cell 1988;52:185-95.

19 Peabody DS. Translation initiation at non-AUG triplets in mammalian cells. F Biol Chem 1989;264:5031-5.

20 Mules EH, Hayflick S, Miller CS, Reynolds LW, Thomas GH. Six novel deleterious and three neutral mutations in the gene encoding the $\alpha$-subunit of hexosaminidase $A$ in non-Jewish individuals. Am 7 Hum Genet 1992;50:83441.

21 Neote K, Mahuran DJ, Gravel RA. Molecular genetics of $\beta$-hexosaminidase deficiencies. In: Rowland PW, ed. $A d$ vances in neurology. New York: Raven Press, 1991:189207.

22 Hubbes $M$, Callahan J, Gravel RA, Mahuran DJ. The amino-terminal sequences in the pro- $\alpha$ and $-\beta$ polypeptides of human lysosomal $\beta$-hexosaminidase $A$ and $B$ are retained in the mature enzymes. FEBS Lett 1989 249:316-20.

23 Korneluk RG, Mahuran DJ, Neote K, et al. Isolation of cDNA clones coding for the $\alpha$-subunit of human $\beta$ hexosaminidase. F Biol Chem 1986;261:8407-13.

24 Myerowitz R, Piekarz R, Neufeld EF, Shows TB, Suzuki $\mathrm{K}$. Human $\beta$-hexosaminidase $\alpha$-chain: coding sequence K. Human $\beta$-hexosaminidase $\alpha$-chain: coding sequence and homology with

25 Proia RL. Gene encoding the human $\beta$-hexosaminidase $\beta$ chain: extensive homology of intron placement in the $\alpha$ and $\beta$-chain genes. Proc Natl Acad Sci USA 1988; 85:1883-7.

26 Beccari T, Hoade J, Orlacchio A, Stirling J. Cloning and sequence analysis of a cDNA encoding the $\alpha$-subunit of mouse $\beta-\mathrm{N}$-acetylhexosaminidase and comparison with the human enzyme. Biochem $\mathcal{f}$ 1992;285:593-6.

27 Bapat B, Ethier M, Neote K, Mahuran D, Gravel RA Cloning and sequence analysis of a CDNA encoding the $\beta$ subunit of mouse $\beta$-hexosaminidase. FEBS Lett subunit of mous

28 Graham TR, Zassenhaus HP, Kaplan A. Molecular cloning of the cDNA which encodes $\beta-N$-acetylhexosaminidase $A$ from Dictyostelium discoideum. If Biol Chem 1988; 263:16823-9.

29 Proia RL, Neufeld EF. Synthesis of $\beta$-hexosaminidase in cell-free translation and in intact fibroblasts: an insoluble precursor $\alpha$-chain in a rare form of Tay-Sachs disease. Proc Natl Acad Sci USA 1982;79:6360-4.

30 Ohno $\mathrm{K}$, Suzuki $\mathrm{K}$. Mutation in $\mathrm{G}_{\mathrm{M} 2}$ gangliosidosis B1 variant. $\mathcal{F}$ Neurochem 1988;50:316-8. 